\title{
South African tobacco smoking cessation clinical practice guideline
}

\author{
R N van Zyl-Smit, ${ }^{1,23}$ MB ChB, MRCP (UK), FCP (SA), Dip HIV Man (SA), MMed, Cert Pulm (SA), PhD; \\ B Allwood, ${ }^{1,2} \mathrm{MB}$ BCh, DCH (SA), DA (SA), FCP (SA), MPH, Cert Pulm (SA); D Stickells, ${ }^{4}$ MB ChB, FCP (SA); \\ G Symons, ${ }^{2}$ MB ChB, FCP (SA), Cert Pulm (SA); S Abdool-Gaffar, ${ }^{5}$ MB ChB, FCP (SA), FCCP; K Murphy, ${ }^{3}$ PhD; \\ U Lalloo, ${ }^{6} \mathrm{MB}$ ChB, FCCP, FRCP (UK); A Vanker, ${ }^{7} \mathrm{MB}$ ChB, FCPaed, MMed, Cert Pulm Paed; \\ K Dheda,${ }^{1,2} \mathrm{MB}$ BCh, FCP (SA), FCCP, PhD, FRCP (UK); G A Richards, ${ }^{8} \mathrm{MB} B C h, \mathrm{PhD}, \mathrm{FCP}(\mathrm{SA})$, FRCP \\ ${ }^{1}$ University of Cape Town Lung Institute, Department of Medicine, University of Cape Town, South Africa \\ ${ }^{2}$ Division of Pulmonology, Department of Medicine, University of Cape Town, South Africa \\ ${ }^{3}$ Chronic Disease Initiative for Africa, University of Cape Town, South Africa \\ ${ }^{4}$ Pulmonologist, Private Practice, Port Elizabeth, South Africa \\ ${ }^{5}$ Pulmonologist, Private Practice, Durban, South Africa \\ ${ }^{6}$ Department of Pulmonology and Critical Care, School of Clinical Medicine, Nelson R Mandela College of Medicine, \\ University of KwaZulu-Natal, Durban, South Africa \\ ${ }^{7}$ Department of Paediatrics and Child Health, Red Cross War Memorial Children's Hospital, University of Cape Town, South Africa \\ ${ }^{8}$ Departments of Critical Care and Pulmonology, Charlotte Maxeke Johannesburg Academic Hospital and \\ University of the Witwatersrand, Johannesburg, South Africa
}

This guideline has been complied on behalf of the South African Thoracic Society to provide practising clinicians with a resource from which to base individual cessation interventions for patients within the South African environment.

Corresponding author: $R$ N van Zyl-Smit (richard.vanzyl-smit@uct.ac.za)

\begin{abstract}
Tobacco smoking (i.e. cigarettes, rolled tobacco, pipes, etc.) is associated with significant health risks, reduced life expectancy and negative personal and societal economic impact. Smokers have an increased risk of cancer (i.e. lung, throat, bladder), chronic obstructive pulmonary disease (COPD), tuberculosis and cardiovascular disease (i.e. stroke, heart attack). Smoking affects unborn babies, children and others exposed to second hand smoke. Stopping or 'quitting' is not easy. Nicotine is highly addictive and smoking is frequently associated with social activities (e.g. drinking, eating) or psychological factors (e.g. work pressure, concerns about body weight, anxiety or depressed mood). The benefits of quitting, however, are almost immediate, with a rapid lowering of blood pressure and heart rate, improved taste and smell, and a longer-term reduction in risk of cancer, heart attack and COPD. Successful quitting requires attention to both the factors surrounding why an individual smokes (e.g. stress, depression, habit, etc.) and the symptoms associated with nicotine withdrawal. Many smokers are not ready or willing to quit and require frequent motivational input outlining the benefits that would accrue. In addition to an evaluation of nicotine dependence, co-existent medical or psychiatric conditions and barriers to quitting should be identified. A tailored approach encompassing psychological and social support, in addition to appropriate medication to reduce nicotine withdrawal, is likely to provide the best chance of success. Relapse is not uncommon and reasons for failure should be addressed in a positive manner and further attempts initiated when the individual is ready.

Key steps in smoking cessation include: (i) identifying all smokers, alerting them to the harms of smoking and benefits of quitting; (ii) assessing readiness to initiate an attempt to quit; (iii) assessing the physical and psychological dependence to nicotine and smoking; (iv) determining the best combination of counselling/support and pharmacological therapy; $(v)$ setting a quit date and provide suitable resources and support; ( vi) frequent follow-up as often as possible via text/telephone or in person; ( $v i i)$ monitoring for side-effects, relapse and on-going cessation; and (viii) if relapse occurs, providing the necessary support and encourage a further attempt when appropriate.
\end{abstract}

S Afr Med J 2013;103(11):869-876. DOI:10.7196/SAMJ.7484

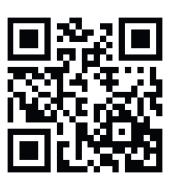

\section{Tobacco smoking in South Africa}

There are an estimated 1.3 billion smokers worldwide and over 5 million deaths per year attributable to tobacco smoking. ${ }^{[1]}$ Even though smoking rates are declining, there are an estimated 7 million smokers in South Africa (SA). ${ }^{[2]}$ Tobacco smoking is undoubtedly the primary risk factor for chronic obstructive pulmonary disease (COPD), which is estimated to be the third highest cause of death globally by 2030 . SA has a particularly high prevalence of smoking $(20 \%))^{[3,4]}$ SA also has one of the highest burdens of tuberculosis (TB) and HIV, which are both risk factors for COPD and exacerbate the effects of smoking. ${ }^{[5,6]}$ Tobacco smoking increases the risk for TB, cancer, pneumonia, ischaemic heart disease and stroke, which are all leading causes of death globally. ${ }^{[1]}$ The mortality among current smokers in SA is nearly double that of nonor ex-smokers. ${ }^{[7,8]}$ Up to a third of all male deaths in SA adults over the age of 35 years have recently been attributed to tobacco use. ${ }^{[7,9]}$ Passive smoking also increases the risk of cardiovascular disease in adults and respiratory disease, particularly among children. The cost of smokingrelated disease to the SA economy is estimated to be R1.2 billion. ${ }^{[10]}$

The benefits of stopping smoking are almost immediate, with a lowering of blood pressure within minutes, and longer-term benefits 
such as improved lung function and reduced risk for lung cancer, stroke and heart disease. Smoking cessation is a critical component of the effective management of COPD. ${ }^{[11]}$ Savings of disposable income, achieved by quitting smoking, would also be available for basic necessities, particularly for those living in poverty.

Many smokers have no desire to quit and will require repeated engagement by health practitioners to affect behaviour change. Interviewing techniques have changed from the more traditional approach, typified by scolding or lecturing, to one that involves support, encouragement and the provision of information. ${ }^{[12]}$ For those who wish to stop there are many options available such as 'cold turkey', cognitive behavioural therapy, acupuncture, hypnosis, internet and cellular phone-based support programmes, and medication.

This guideline assesses published evidence and reviews international guidelines, applying them to the specific needs and circumstances in SA in developing a clinical practice guideline for SA clinicians.

Published international guidelines from the US Centers for Disease Control, the American College of Chest Physicians (ACCP), the UK National Institute for Clinical Excellence (NICE) and the Cochrane Collaboration Database of Systematic Reviews for all topics relating to tobacco smoking were reviewed. In addition, PubMed was searched for newer studies on specific topics such as e-cigarettes, smoking in pregnancy, and smoking in persons infected with HIV or TB. Smoking in this guideline refers to all forms of smoking tobacco products such as cigarettes, cigars and rolled tobacco. Smoking cessation - also referred to as quitting, is the process of stopping smoking. Where available, evidence grading is provided with the grading source.

\section{Tobacco smoking cessation strategies}

Smoking cessation can be broadly divided into two phases: (i) the identification of smokers and assisting them to quit; and (ii) initiating and sustaining the quit attempt (Fig. 1). The strength of evidence for each intervention varies. For each stage and intervention, key points and strength of supporting data are presented and expert opinion was relied on where data was lacking.

\subsection{Identifying smokers and initiating quit attempts}

- The strategy of identifying smokers during routine consultations with healthcare practitioners increases quit attempts (Grade $\mathrm{A}^{[13]}$ ).

- Brief smoking cessation interventions should be implemented, regardless of the availability of, and access to, specialised services $\left(\right.$ Grade $\left.\mathrm{A}^{[13]}\right)$.

'If you don't think about it, you won't do it'. Using stickers, tags or reminders in folders for the nurses or doctors increases the likelihood of discussions with patients around smoking, counselling and referral for cessation advice. The inclusion of smoking as one of the vital signs identifies $80 \%$ or more of smokers attending primary care facilities. ${ }^{[14]}$

\subsection{Clinical interventions to initiate and sustain smoking cessation}

- Repeated encouragement and assistance provided by more than one physician/healthcare worker, through a range of supportive options, increase the likelihood of abstinence (Grade $\left.\mathrm{A}^{[13]}\right)$.

Interventions as brief as 3 min can significantly increase quit rates, but intensive interventions are more effective (more comprehensive treatments being those that occur over multiple visits, for a longer period of time and/or are provided by more than one clinician). ${ }^{[14]}$ The goal should be for every tobacco user to be identified and offered at least a brief intervention at every clinical consultation. A commonly recommended approach is the 5As model, which is an effective, structured approach to providing brief interventions (3-10 $\mathrm{min}$ ) in the primary care setting. The 5 steps are: (i) asking about smoking; (ii) alerting the patient to the benefits of quitting; (iii) assessing readiness to make a quit attempt; (iv) assisting those willing to quit; and $(v)$ arranging for follow-up contact and referral to further resources, such as quitlines. Problem solving, skills training and psychosocial support during treatment are all effective elements of counselling. They can be used as part of brief interventions, but also form the foundation of more intensive interventions. ${ }^{[14]}$

\subsection{Motivational interviewing approach}

Many patients lack the motivation to quit or express a lack of readiness to quit. This may be because they lack information, have concerns about quitting, face significant social/environmental barriers or lack confidence in their ability to quit. Such patients may benefit from counselling methods derived from motivational interviewing $(\mathrm{MI}){ }^{[12]}$

In this approach, the clinician encourages the smoker to explore their feelings of ambivalence about smoking/quitting by discussing, for example, the pros and cons of smoking from their perspective, and by exploring how personally important cessation may be and how confident they feel about it. In this process, the provider supports and strengthens any intentions to change, which come from the patients themselves. The idea is to elicit self-motivational statements, rather than tell the patient what they should do and how they should do it. MI posits that a good collaborative relationship, in which a client is viewed as the expert on his/her own life, serves to minimise resistance to change and thereby enhances motivation. ${ }^{[15]}$ This varies significantly from the traditional, advice-giving approach, which casts the provider in a dominant, directing role and the patient merely as a passive recipient of their expert knowledge. Metaanalyses have shown that MI can significantly improve smoking cessation rates over brief advice. ${ }^{[16]}$

\subsection{The individual who is not ready to quit}

- Encourage the individual to think about quitting, identify the reasons for smoking and the barriers to quitting and provide an opportunity for follow-up.

For individuals who are not ready or willing to quit, on-going encouragement and offers of support are necessary. The practitioner can provide information about the risks of smoking and the benefits of quitting and encourage the patient to return for further discussions if and when they are ready to quit. Assisting the patient to identify the perceived benefits that they gain from smoking (i.e. stress reduction, weight control), their perceived barriers to quitting (i.e. social pressure, withdrawal symptoms) and the benefits of quitting (i.e. health improvement, cost savings) can lay the foundation to behavioural change at a later date and enhance the possibility of a quit attempt.

\subsection{Assisting the motivated patient to quit}

- Counselling plus medication to treat nicotine withdrawal is more effective than either intervention alone (Grade $\mathrm{A}^{[13]}$ ).

- Multiple options are available and can be tailored to suit the individual patient and circumstance.

- Smokers who are motivated, have supportive networks and are ready to change, have higher success rates.

- Smokers who are highly nicotine dependent, have social stressors and psychiatric comorbidities, are less likely to be successful. 


\section{GUIDELINE}

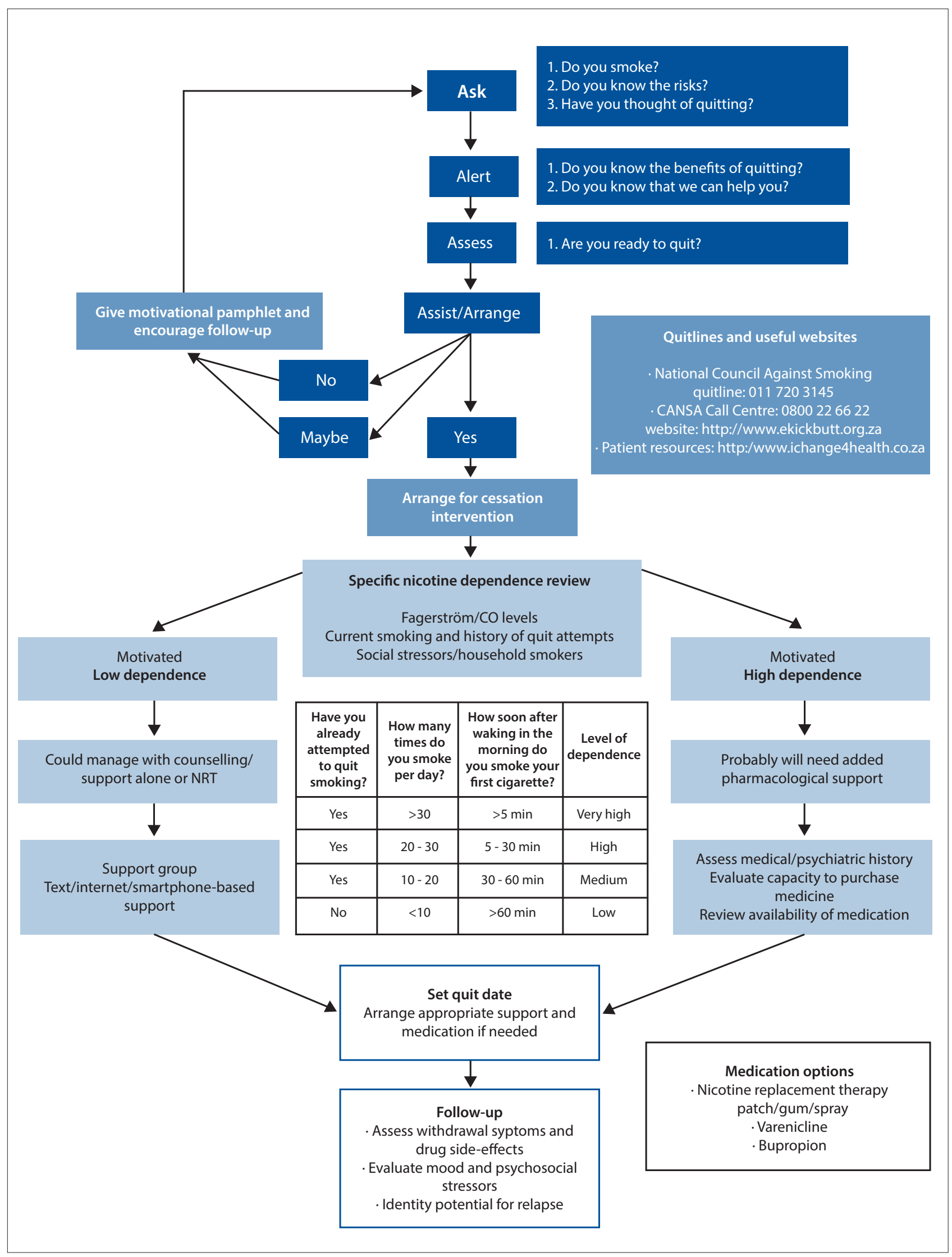

Fig. 1. Smoking cessation approach in clinical practice. All smokers should be identified and their readiness to quit evaluated. If resistance to quitting exists, information and suitable follow-up should be provided (top). If an individual is ready to make a quit attempt, evaluation of nicotine dependence, co-morbid disease and psychosocial factors should guide the clinician in the choice of effective interventions (bottom). $C O=$ carbon monoxide; NRT = nicotine replacement therapy. 


\section{Pharmacological intervention (drug treatment to aid smoking cessation)}

Several pharmacological strategies are available to assist in smoking cessation - predominantly to address acute nicotine withdrawal. These may be simply classified as nicotine replacement therapies (NRTs) or drugs that reduce addiction. Although both classes of drug are an aid to smoking cessation, they have little or no effect on the underlying addiction and do not address the psychosocial factors that cause a person to smoke. Most studies of pharmacological interventions have been conducted in subjects who smoke $>10$ cigarettes/day and frequently $>20$ cigarettes/day. There is little evidence to guide the use of pharmacological therapy in subjects who smoke only 3 - 5 cigarettes/day or in those with very low nicotine dependence. Table 1 outlines the comparative performance of the various drugs available to assist in smoking cessation.

\subsection{NRT}

- NRT is effective and should be encouraged (Grade $\mathrm{A}^{[13]}$ ).

- A controller (patch) and reliever (gum, spray) approach is the most effective way to use NRT (Grade $\mathrm{A}^{[13]}$ ).

NRT has been the mainstay for addressing nicotine withdrawal. It is particularly effective when employing dual NRT - one as a 'controller' and one as a 'reliever' (odds ratio (OR) 3.6 (95\% confidence interval (CI) 2.5 - 5.2) for success, and abstinence rates 36.5\% (95\% CI 28.6 - 45.3) at the end of therapy). ${ }^{[14]}$ This approach, which is advocated by the ACCP, is more effective than using a single form of NRT (relative risk (RR) 1.34; 95\% CI 1.18 - 1.51). ${ }^{[17]}$ Titration of the NRT (via patch strength) to the level of symptom severity based on the Fagerström scale (Table 2), or of cotinine level is recommended to ensure that adequate control of withdrawal symptoms is achieved. If 'breakthrough' symptoms occur the 'reliever' NRT should be used (gum, spray, etc.) The use of nicotine spray may be preferred to gum in some individuals. ${ }^{[18]}$ Combinations of NRT with bupropion are more effective than NRT alone (OR 2.57; 95\% CI 1.05 - 6.32), ${ }^{\left[{ }^{[19]}\right.}$ but based on the theory of their mechanism of action, there should be no value in using both NRT and varenicline together. Despite this, there are anecdotal reports of additional benefit, and this has recently been tested in the VARNIC study, the results of which are expected during 2014. Note: at the time of writing these practice guidelines, nicotine patches were not available in SA.

\subsection{Antidepressants}

- Bupropion is an effective drug for smoking cessation particularly in combination with NRT (Grade $\mathrm{A}^{[13]}$ ).

- Nortriptyline is a moderately effective drug for smoking cessation (Grade $\mathrm{A}^{[13]}$ ).

- The use of bupropion or nortriptyline must be under medical supervision due to potential side-effects and interactions.

Bupropion (Zyban) used at doses of $150 \mathrm{mg}$ twice daily for 7 - 12 weeks is effective (RR 1.69; 95\% CI 1.53 - 1.85). ${ }^{[20]}$ Additionally, bupropion appears to reduce long-term relapse and the weight gain associated with quitting. ${ }^{[2]]}$ Its most frequent side-effects are insomnia, dry mouth and nausea. ${ }^{[20]}$ Bupropion may also reduce the seizure threshold and a seizure risk of $1 / 1000$ has been reported. ${ }^{[2]}$ There is no evidence that selective serotonin re-uptake inhibitors (SSRIs) are effective for smoking cessation. ${ }^{[20]}$

Nortriptyline (not registered in SA) is generally considered a secondline therapy for those who have failed NRT and bupropion/varenicline. ${ }^{[23]}$ Nortriptyline is a metabolite of amitriptyline, which is available in SA. There are, however, no published data on smoking cessation using amitriptyline. Given the increased associated risk of suicide in smokers ${ }^{[2,2,25}$ the serious complications of amitriptyline overdose and its unknown efficacy as a smoking cessation aid, the drug cannot be recommended for smoking cessation until further data are available.

\subsection{Nicotine receptors agonists}

- Varenicline is an effective smoking cessation therapy (Grade $\mathrm{A}^{[13]}$ ). - Although not confirmed in large studies and meta-analyses, there is concern about incidents of suicide or suicidal behaviour.

- It is strongly advised that all patients who are prescribed these drugs are closely monitored for behavioural change and/or neuropsychiatric symptoms.

Two nicotine receptor partial agonists have been marketed: varenicline (Champix - registered in SA) and cytisine (Tabex not registered in SA). By acting as partial agonists, they stimulate dopamine release and reduce nicotine withdrawal symptoms. ${ }^{[2-28]}$ In controlled trials and meta-analyses, varenicline has been shown to be the most effective single drug for smoking cessation (RR 3.1; $95 \%$ CI $2.5-3.8)^{[2,30]}$ whereas cytisine, although effective, appears to result in only a modest increase in quit rates. ${ }^{[2,31]}$ The most common side-effects reported with varenicline include abnormal dreams,

Table 1. Comparisons of abstinence rates achieved with different pharmacological interventions to support smoking cessation*

\begin{tabular}{|c|c|c|c|}
\hline Medication & Arm, $n$ & OR $(95 \% \mathrm{CI})$ & Estimated abstinence rate $(95 \% \mathrm{CI})$ \\
\hline Placebo & 80 & 1 & 13.8 \\
\hline \multicolumn{4}{|l|}{ NRT } \\
\hline Nicotine gum & 15 & $1.5(1.2-1.7)$ & $19(16.5-21.9)$ \\
\hline Nicotine patch & 32 & $1.9(1.7-2.2)$ & $23.4(21.3-25.8)$ \\
\hline Nicotine spray & 4 & $2.3(1.7-3)$ & $26.7(21.5-32.7)$ \\
\hline \multicolumn{4}{|c|}{ Antidepressants/centrally acting agents } \\
\hline Bupropion SR & 26 & $2(1.8-2.2)$ & $24.2(22.2-26.4)$ \\
\hline Nortriptyline & 5 & $1.8(1.3-2.6)$ & $22.5(16.8-29.4)$ \\
\hline Clonidine & 3 & $2.1(1.2-3.7)$ & $25(15.7-37.3)$ \\
\hline \multicolumn{4}{|l|}{ Nicotine receptor agonist } \\
\hline Varenicline ( $2 \mathrm{mg} /$ day $)$ & 5 & $3.1(2.5-3.8)$ & $33.2(28.9-37.8)$ \\
\hline
\end{tabular}


Table. 2. Fagerström test for nicotine dependence ${ }^{[85}$

\begin{tabular}{ll}
\hline Question & Score \\
\hline 1. How soon after you wake up do you smoke your first cigarette? & \\
Within 5 min & 3 \\
$6-30 \mathrm{~min}$ & 2 \\
$31-60 \mathrm{~min}$ & 1 \\
After $60 \mathrm{~min}$ & 0 \\
2. Do you find it difficult to refrain from smoking in places where it is & \\
forbidden? & 1 \\
Yes & 0 \\
No &
\end{tabular}

3. Which cigarette would you hate most to give up?

The first in the morning

Any other

4. How many cigarettes per day do you smoke?

$\leq 10$

$11-20$

$21-30$

$\geq 31$

5. Do you smoke more frequently during the first hours after waking than during the rest of the day?

Yes

No

6. Do you smoke even if you are so ill that you are in bed most of the day?

Yes

No

TOTAL SCORE

Interpretation of total score ${ }^{[86]}$

$\begin{array}{ll}0-3 & \text { Mild dependence } \\ 4-6 & \text { Moderate dependence } \\ 7-10 & \text { Severe dependence }\end{array}$

nausea and headache. ${ }^{[32,33]}$ While smokers as a group are at higher risk of suicide than non-smokers, ${ }^{[24,25]}$ there are concerns about the neuropsychiatric side-effects of varenicline. While the US Food and Drug Administration (FDA) mandated a black box' warning in 2008, meta-analyses have not confirmed this risk. ${ }^{[29,34]}$ Recent studies have also reported that varenicline appears to be safe in patients with schizophrenia ${ }^{[35]}$ and in patients with cardiac disease. . $29,36-38]^{-35}$ Nevertheless, it should be used with caution and under supervision. Champix is a schedule 5 drug in SA and patients should be monitored regularly with particular attention to changes in their emotional state, unusual behaviour and suicidal ideation.

\subsection{Electronic cigarettes}

- There is no evidence that electronic cigarettes (e-cigarettes) are effective aids to smoking cessation, although they may reduce the number of cigarettes smoked.

E-cigarettes are battery-powered devices, similar in appearance to conventional cigarettes that vaporise nicotine. A large variety of products are on offer. They are available in different flavours and may be used in an attempt to reduce the symptoms of nicotine withdrawal while allowing the smoker to participate in the 'ritual' of smoking. E-cigarettes are available over the counter and there is currently little legislative control on their use, availability and marketing. Recently however, both the FDA and the South African Medicines Control Council have begun to consider regulation of these products. ${ }^{[39]}$

The role of e-cigarettes in smoking cessation algorithms remains unclear. As they are likely to be less hazardous than tobacco smoking, ${ }^{[40]}$ they may, in future, have a role in smoking cessation, either to reduce nicotine intake or as a bridge to smoking cessation. In a small pilot study, they appeared to decrease cigarette consumption, ${ }^{[4]]}$ and they may be especially useful in reducing consumption in chronic psychiatric (schizophrenic) patients. ${ }^{[42]}$ Sideeffects include mouth and throat irritation, dry cough, nausea and headache, although these appear to decrease over time. Concerns have been raised about the long-term safety of e-cigarettes, particularly with regard to the flavouring used. ${ }^{[43]}$ Additionally, although e-cigarettes do not produce classic smoke, they have been found to produce short-term adverse physiological effects on the airways. ${ }^{[4]]}$ Currently, given the lack of data on efficacy and limited long-term safety data, they are not recommended as part of smoking-cessation strategies.

\subsection{Nicotine vaccine}

- The theory behind nicotine vaccines is that they induce antibodies that bind to nicotine, reducing its availability to central receptors.

- Nicotine vaccines are still in development and their efficacy has not been confirmed. ${ }^{[5]}$

\subsection{Complementary medicine}

Several forms of complementary medical approaches are in common use and are widely advertised as aids to smoking cessation. These include hypnotherapy, acupuncture, acupressure and electro-stimulation. However, none of these methods are supported by convincing efficacy data when subjected to review using Cochrane Library methods. Although positive results have been reported in individual studies, there is a lack of data from large, randomised, controlled studies. When performed by experienced and qualified individuals, they are likely to be safe and may benefit some. However, they are not recommended as effective strategies.

\subsubsection{Hypnotherapy}

- There is no evidence to support hypnotherapy as an effective aid to smoking cessation.

Hypnotherapy is a widely promoted aid to smoking cessation and multiple approaches, techniques and success rates have been reported. Two recently published metaanalyses, in which different study selection criteria were employed, concluded that hypnotherapy was not effective, as insufficient quality data existed comparing hypnotherapy with other methods for smoking cessation. Estimates in the two separate meta-analyses for success of hypnotherapy in achieving smoking cessation were: OR $4.55\left(95 \% \mathrm{CI} 0.98\right.$ - 21.01) ${ }^{[46]}$ and RR 1.49 (95\% CI $0.86-2.5)^{[47]}$ 


\subsubsection{Acupuncture}

- 'There is no consistent, evidence that either acupuncture or acupressure are effective in smoking cessation. ${ }^{\text {[48] }}$

Several studies and meta-analyses have evaluated the effects of acupuncture on smoking cessation in a controlled, randomised manner. ${ }^{[4.50]}$ Differing methods used in these studies (e.g. the nature of control procedures and the selection of control groups) do not provide sufficient consistency for a bias-free analysis. The most recent and comprehensive Cochrane review concluded that acupuncture is less effective than NRT (RR 1.05; 95\% CI 0.82 - 1.35) ${ }^{[48]}$

\section{Smoking cessation in specific situations \\ 4.1 Pregnancy}

- Smoking poses significant risks to mother and fetus.

- Brief counselling by a healthcare provider as part of routine antenatal care is effective and well received by pregnant women.

- There is, as yet, insufficient, high-quality evidence to determine whether the use of pharmacotherapy (i.e. NRT, bupropion or varenicline) is effective and safe during pregnancy.

The risks to mother and child from smoking during pregnancy, and in the post-natal period are well established. Maternal smoking is associated with obstetric risks (miscarriage and premature rupture of membranes, placental abruption, intra-uterine growth retardation and stillbirth). ${ }^{[51]}$ Maternal exposure to second-hand smoke in pregnancy can also increase the risk of low-birthweight children. ${ }^{[52]}$ Although quitting early in pregnancy will produce the greatest benefits, stopping at any stage during pregnancy yields benefits to the fetus and mother, and the child in the postnatal period. ${ }^{[53]}$ Passive smoking increases the risk for asthma, middle ear and recurrent chest infections in children. ${ }^{[5]}$ Counselling should be offered at the first antenatal visit and if possible, smokers in the household or workplace should be identified. A smoking cessation intervention involving brief counselling by lay counsellors, supported by midwives and by educational materials specifically tailored to pregnancy, was shown to be effective in increasing cotinine-validated quit rates among disadvantaged women attending public sector antenatal care clinics in SA. ${ }^{[55]}$ On the basis of the substantial evidence of benefit from NRT in the general population and the limited evidence available among pregnant women, ${ }^{[3,5,5,5]}$ some guidelines recommend the use of NRT in pregnancy under medical supervision, but only when behavioural therapy has failed and in heavily dependent smokers who remain motivated to quit. ${ }^{[58]}$

\subsection{Adolescents/paediatrics}

- Treatment strategies relying on behavioural change are effective.

- No smoking cessation medication is licensed for use in children aged less than 18 years.

- Paediatricians and healthcare workers providing care to children must address smoking by parents and advise on smoking-cessation strategies.

Tobacco smoking in adolescents frequently leads to long-term nicotine addiction and the consequent adverse health-effects. In SA in $2008,21 \%$ of learners (grade 8 - 10) were found to be current smokers, with $6.8 \%$ having initiated smoking before the age of 10 years. ${ }^{[59]}$ The smoking of hookah pipes ('hubbly-bubbly') should be addressed among adolescents who frequently believe it to be tobaccofree and, hence, safe. Preventing adolescents from starting to smoke is vital to reduce the numbers of adults who smoke.
Nearly half of adolescent smokers in SA attempt to quit each year but factors such as stress, depression, peer pressure and weight gain impact on their success. ${ }^{[59-62]}$ Behavioural change can be encouraged by focussing on the health benefits and improved school and sport performance, and by recognising the effects of cultural differences and the social pressures that exist with regard to smoking. ${ }^{[6-62]} \mathrm{A}$ variety of methods (ranging from one-on-one sessions to group therapy, telephonic helplines and web-based programmes) have been tried and, if tailored to individual needs, may double success rates. There are insufficient studies comparing these models in order to recommend one particular strategy in adolescents. ${ }^{[13,63]}$ It is imperative to speak to the adolescent alone (without the caregiver present) and to maintain confidentiality when encouraging behavioural change.

SA data show that adolescents who have been exposed to smokers are more likely to smoke than those who have not $(74.5 \%$ v. $44 \%$, respectively). ${ }^{[59]}$ Counselling of parents on the harmful effects of smoking and on interventions to aid quitting may reduce secondary smoke exposure in children. ${ }^{[13]}$ Parental smoking cessation is also associated with higher quit rates among adolescents. ${ }^{[2,64]}$

No smoking-cessation medications are FDA-approved in children or adolescents (under 18 years). The UK NICE guidelines, however, support the use of NRT if required, along with behavioural interventions in teenagers over 12 years of age.$^{[58]}$ If a decision is made to use NRT in a teenager, it should be used in conjunction with behavioural therapy and should be individualised. Although safety studies have been conducted with bupropion and varenicline in adolescents, both are only approved for adults in SA. ${ }^{[33]}$

\subsection{Tuberculosis}

- Smokers have approximately double the risk of developing TB and of dying from TB than non-smokers.

- Smoking cessation for people with active TB is a feasible and effective intervention.

There is substantial epidemiological evidence that smokers have a higher risk of developing TB (both latent and active) and dying

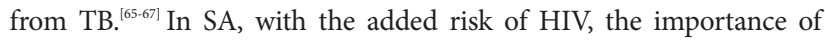
smoking cessation to reduce the risk of TB, HIV-related diseases and COPD is unquestionable. ${ }^{[6,68]}$ There are some data to show that integrating smoking cessation efforts (support plus NRT) with TB treatment is feasible ${ }^{[69]}$ improves quit rates (77\% v. 8.7\%, respectively) and completion of $\mathrm{TB}$ treatment $\left(97.5 \%\right.$ v. $84.8 \%$, respectively). ${ }^{[70]}$ It is unclear, however, whether stopping smoking during TB therapy will reduce the excess mortality associated with smoking and $\mathrm{TB},{ }^{[7] 1}$ nor are there any efficacy data available on whether using bupropion or varenicline with concomitant anti-TB therapy may be of benefit. Smoking cessation should, however, be encouraged in all TB patients and appropriate support provided.

\subsection{HIV/antiretroviral therapy}

- Smoking cessation is an important and effective intervention in individuals living with HIV.

- Drug-drug interactions may occur with bupropion.

The risks of smoking in HIV-infected individuals are well described and include inter alia pneumonia, TB and lung cancer. ${ }^{[72]}$ There are several small trials on smoking cessation in the context of HIV that have concluded that it is an important and effective intervention. ${ }^{[72-74]}$ Smoking and nicotine are known to induce hepatic enzymes, ${ }^{[7,76]}$ but not those metabolising common antiretrovirals (ARVs). Enzyme inhibition/induction by ARVs such as lopinavir-ritonavir may 
increase or reduce serum concentrations of bupropion and should be used with caution. ${ }^{[7]}$ Varenicline is not metabolised by the liver, thus drug-drug interactions should not occur, but common side-effects such as nausea may interfere with ARV compliance. ${ }^{[73]}$

\subsection{Mental illness}

- Smoking is common in individuals with mental illness.

- Adequate management of the underlying psychiatric illness is key to successful smoking cessation.

Anxiety disorders, depression, and schizophrenia are strongly associated with tobacco smoking. ${ }^{[3,77778]}$ There is evidence to suggest that psychiatric disorders may lead to self-medication with nicotine and that smoking may predispose individuals to mental illness. ${ }^{[8,79]}$ Smoking cessation is important even in those with complex psychiatric disorders. Where necessary, consultation with an experienced psychiatrist may be beneficial in choosing the best options for management of the mental illness and drugs for smoking cessation if required. A recent Cochrane review concluded that bupropion and varenicline appear to be safe and effective in schizophrenia, but NRT and psychological interventions show no benefit. ${ }^{[3]}$ In patients with current depression, management of the depression should be addressed first, as there is limited success of smoking cessation interventions (even bupropion). ${ }^{[77]}$

\subsection{In-hospital cessation}

- In-hospital cessation counselling with post-discharge follow-up is an effective intervention to assist in smoking cessation.

- The addition of NRT substantially improves quit rates, but insufficient data exist as to the additional benefits of bupropion or varenicline.

As smoking is banned in most public places and particularly in hospitals, acute admissions in which smoking cessation is imposed are convenient opportunities to promote smoking cessation. Many trials have demonstrated that appropriate in-hospital counselling and postdischarge follow-up are effective. ${ }^{[80]}$ The additional use of NRT appears to be highly effective (54\% increase in cessation rates). ${ }^{[80]}$ There are insufficient data concerning the use of bupropion or varenicline during hospitalisation. Acute pre-operative cessation has mixed reports of longterm success, although lower complication rates (in relation to wound healing and lung function) occur in those who quit at least $6-8$ weeks prior to surgery. ${ }^{[81-84]}$

\section{Relapse}

Relapse is common; frequently, because the underlying psychosocial factors or nicotine addiction have not been adequately addressed. Relapses can be viewed as an opportunity to learn how to approach a subsequent quit attempt, rather than as outright failure. Many attempts may be required before long-term success is achieved. If relapse does occur, appropriate support should be provided and the reasons for relapse reviewed before another quit attempt.

\section{Implementation and further research}

Smoking cessation at the primary level will require adequate training of staff to provide the necessary counselling to motivate patients to attempt to quit. Lay counsellors providing HIV adherence support could be trained to offer smoking cessation counselling and support. The prescription of medication to support quit attempts may need to be restricted to clinicians/clinics who are able to fully assess nicotine dependence and monitor side-effects of the medication. Research into the optimal use of medications in HIV/TB patients as well as the possible use of amitriptyline is needed.

\section{Summary and recommendations}

Nicotine addiction and psychosocial stressors make smoking cessation difficult, even in those who are motivated to quit. Motivating those with no apparent interest in quitting nor confidence to quit, requires support and encouragement from healthcare practitioners at every contact and should involve the entire health team. Although time is limited in clinical practice, brief motivational counselling with appropriate referral of the individual who is motivated to quit, is effective.

These practice guidelines serve as an aid to the clinician in deciding on the best strategies to use for smoking cessation. Even the best programmes internationally have only modest success rates, with frequent relapses if the underlying reasons predisposing to smoking or the barriers to cessation have not been addressed. Informing the smoker about the immediate and long-term benefits of quitting, anticipating the difficulties that could be expected and problem solving with the patient, as well as prescribing appropriate medication where needed, all increase the possibility of success. If such interventions are widely applied to a large proportion of smokers, they have the potential to achieve important reductions in disease and associated excess healthcare costs.

Acknowledgements. The South African Thoracic Society guideline committee is grateful to Professors Eric Bateman and Dan Stein for their input and review of this guideline.

Conflicts of interest. None of the authors have any relationship with the tobacco industry. No funding was received from any source to prepare these guidelines. RVZS, DS and GR have received honoraria from Pfizer, GSK (DS, GR). GR, DS and SAG have been on advisory committees for Pfizer and GSK (SAG),

\section{References}

1. World Health Organization. WHO Report on the Global Tobacco Epidemic, 2008. The MPOWER Package. Geneva: WHO, 2008. http://www.who.int/tobacco/mpower/mpower_report_full_2008.pdf (accessed 1 October 2013).

2. van Walbeek C. Recent trends in smoking prevalence in South Africa - some evidence from AMPS data. S Afr Med J 2002;92(6):468-472. (Non-US government research support)

3. Buist AS, McBurnie MA, Vollmer WM, et al. International variation in the prevalence of COPD (the BOLD Study): A population-based prevalence study. Lancet 2007;370(9589):741-750. [http://dx.doi.org/10.1016/ S0140-6736(07)61377-4]

World Health Organization. The World Health Report 2002 - Reducing Risks, Promoting Healthy Life. Geneva: WHO, 2002. http://www.who.int/whr/2002/en/ (accessed 1 October 2013).

Crothers $K$. Butt AA Gibert CL et al Increased COPD among HIV-positive compared to HIV-negative veterans. Chest 2006;130(5):1326-1333. [http://dx.doi.org/10.1378/chest.130.5.1326]

6. veterans. Chest 2006,130 J).1326 1333. [htp://dx.doi.org/10.1378/dhest.130.5.1326]

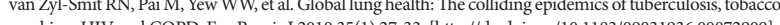
6. Sitas F, Egger S, Bradshaw D, et al. Differences among the coloured, white, black, and other South African populations in smoking-attributed mortality at ages 35-74 years: A case-control study of 481640 deaths. Lancet 2013;382(9893):685-693. [http://dx.doi.org/10.1016/S0140-6736(13)61610-4] (Non-US government research support)

8. Tha P, Ramasundarahettige C, Landsman V, et al. 21st-century hazards of smoking and benefits of cessation in the United States. N Engl J Med 2013;368(4):341-350. [http://dx.doi.org/10.1056/NEJMsa1211128] (Non-US government and US National Institutes of Health (NIH) extramural research support)

Groenewald P, Vos T, Norman R, et al. Estimating the burden of disease attributable to smoking in South Africa in 2000. S Afr Med J 2007;97(8):674-681.

10. Tobacco Atlas Online. http://www.tobaccoatlas.org (accessed 1 October 2013).

11. Warnier MJ, van Riet EE, Rutten FH, et al. Smoking cessation strategies in patients with COPD. Eur Respir J 2013;41(3):727-734. [http://dx.doi.org/10.1183/09031936.00014012]

2. Rollnick S, Butler CC, Kinnersley P, et al. Motivational interviewing. BMJ 2010;340:c1900. [http://dx.doi. Rollnick S, Butler CC,

13. Fiore MC, Jaen CR, Baker TB. Treating Tobacco Use and Dependence: 2008 Update. Rockville: US Department of Health and Human Services, Public Health Service, 2008.

14. Fiore MC. Treating tobacco use and dependence: 2008 update U.S. Public Health Service Clinical Practice Guideline executive summary. Respir Care 2008;53(9):1217-1222.

15. Lundahl B, Burke BL. The effectiveness and applicability of motivational interviewing: A practicefriendly review of four meta-analyses. J Clin Psychol 2009;65(11):1232-12345. [http://dx.doi. org/10.1002/jclp.20638]

6. Lai DT, Cahill K, Qin Y, et al. Motivational interviewing for smoking cessation. Cochrane Database Syst Rev 2010(1):CD006936. [http://dx.doi.org/10.1002/14651858.CD006936.pub2] (Meta-analysis review)

17. Stead LF, Perera R, Bullen C, et al. Nicotine replacement therapy for smoking cessation. Cochrane Database Syst Rev 2012;11:CD000146. [http://dx.doi.org/10.1002/14651858.CD000146.pub4] (Non-US government research support)

18. Bolliger CT, van Biljon X, Axelsson A. A nicotine mouth spray for smoking cessation: A pilot study of preference, safety and efficacy. Respiration 2007;74(2):196-201. [http://dx.doi.org/10.1159/000097136] (Randomised controlled trial (RCT); non-US government research support)

9. Steinberg MB, Greenhaus S, Schmelzer AC, et al. Triple-combination pharmacotherapy for medically ill smokers: A randomized trial. Ann Intern Med 2009;150(7):447-454. 
20. Hughes JR, Stead LF, Lancaster T. Antidepressants for smoking cessation. Cochrane Database Syst Rev 2007(1):CD000031. [http://dx.doi.org/10.1002/14651858.CD000031.pub3] (Meta-analysis review)

21. Hays JT, Hurt RD, Rigotti NA, et al. Sustained-release bupropion for pharmacologic relapse prevention after smoking cessation: A randomized, controlled trial. Ann Intern Med 2001;135(6):423-433. [http://dx.doi. org/10.7326/0003-4819-135-6-200109180-00011] (Clinical RCT; non-US government research support)

22. Dunner DL, Zisook S, Billow AA, et al. A prospective safety surveillance study for bupropion sustainedrelease in the treatment of depression. J Clin Psychiatry 1998;59(7):366-373. [http://dx.doi.org/10.4088/JCP. v59n0705] (Multi-centre, clinical trial; non-US government research support)

23. Hughes JR, Carpenter MJ, Naud S. Do point prevalence and prolonged abstinence measures produce similar results in smoking cessation studies? A systematic review. Nicotine Tob Res 2010;12(7):756-762 [http://dx.doi.org/10.1093/ntr/ntq078] (Comparative study; NIH extramural review research support)

24. Miller M, Hemenway D, Rimm E. Cigarettes and suicide: A prospective study of 50,000 men. Am J Public Health 2000;90(5):768-773. (Non-US government and US Public Health Service (PHS) government research support)

25. Hemmingsson T, Kriebel D. Smoking at age 18-20 and suicide during 26 years of follow-up - how can the association be explained? Int J Epidemiol 2003;32(6):1000-1004. (Non-US government research support)

26. Coe JW, Brooks PR, Vetelino MG, et al. Varenicline: An a $4 \beta 2$ nicotinic receptor partial agonist for smoking cessation. J Med Chem 2005;48(10):3474-3477. [http://dx.doi.org/10.1021/jm050069n] (In vitro study)

27. Gonzales D, Rennard SI, Nides M, et al Varenicline an $\alpha 4 \beta 2$ nicotinic acetylcholine receptor partial agonist, vs sustained-release bupropion and placebo for smoking cessation: A randomized controlled trial. JAMA 2006;296(1):47-55. [http://dx.doi.org/10.1001/jama.296.1.47] (Multi-centre, comparative, clinical phase III RCT; non-US government research support)

28. Jorenby DE, Hays JT, Rigotti NA, et al. Efficacy of varenicline, an $\alpha 4 \beta 2$ nicotinic acetylcholine receptor partial agonist, vs placebo or sustained-release bupropion for smoking cessation: A randomized controlled trial. JAMA 2006;296(1):56-63. [http://dx.doi.org/10.1001/jama.296.1.56] (Multi-centre, comparative, RCT; non-US government research support)

29. Cahill K, Stead LF, Lancaster T. Nicotine receptor partial agonists for smoking cessation. Cochrane Database Syst Rev 2012;4:CD006103. [http://dx.doi.org/10.1002/14651858.CD006103.pub6] (Meta-analysis review; non-US government research support)

30. Brose LS, West R, Stapleton JA. Comparison of the effectiveness of varenicline and combination nicotine replacement therapy for smoking cessation in clinical practice. Mayo Clin Proc 2013;88(3):226-233. [http:// dx.doi.org/10.1016/j.mayocp.2012.11.013]

31. West R, Zatonski W, Cedzynska M, et al. Placebo-controlled trial of cytisine for smoking cessation. N Engl J Med 2011;365(13):1193-1200. [http://dx.doi.org/10.1056/NEJMoa1102035] (RCT; non-US government research support)

32. Fagerstrom K, Hughes J. Varenicline in the treatment of tobacco dependence. Neuropsychiatr Dis Treat 2008;4(2):353-363.

33. Pfizer Laboratories (Pty) Ltd. CHAMPIX Tablet range package insert South Africa. 2010.

34. US Food and Drug administration. FDA drug safety communication: Safety review update of Chantix (varenicline) and risk of neuropsychiatric adverse events, 2011. http://www.fda.gov/Drugs/DrugSafety/ ucm276737.htm (accessed 1 October 2013).

35. Tsoi DT, Porwal M, Webster AC. Interventions for smoking cessation and reduction in individuals with schizophrenia. Cochrane Database Syst Rev 2013;2:CD007253. [http://dx.doi.org/10.1002/14651858. CD007253.pub3] (Meta-analysis; non-US government review research support)

36. Svanstrom H, Pasternak B, Hviid A. Use of varenicline for smoking cessation and risk of serious cardiovascular events: Nationwide cohort study. BMJ 2012;345:e7176. [http://dx.doi.org/10.1136/bmj.e7176]

37. Singh S, Loke YK, Spangler JG, et al. Risk of serious adverse cardiovascular events associated with varenicline: A systematic review and meta-analysis. CMAJ 2011;183(12):1359-1366. [http://dx.doi.org/10.1503/ cmaj.110218] (Meta-analysis; NIH extramural review research support)

38. Sobieraj D. Cardiovascular effects of pharmacological therapies for smoking cessation. J Am Soc Hypertens 2013;7(1):61-67. [http://dx.doi.org/10.1016/.j.jash.2012.11.003]

39. Deyton L, Woodcock J. Regulation of E-Cigarettes and Other Tobacco Products. Public Health Focus, 25 April 2011. http://www.fda.gov/NewsEvents/PublicHealthFocus/ucm252360.htm (accessed 1 October 2013).

40. Flouris AD, Poulianiti KP, Chorti MS, et al. Acute effects of electronic and tobacco cigarette smoking on complete blood count. Food Chem Toxicol 2012;50(10):3600-3. [http://dx.doi.org/10.1016/j. fct.2012.07.025]

41. Polosa R, Caponnetto P, Morjaria JB, et al. Effect of an electronic nicotine delivery device (e-cigarette) on smoking reduction and cessation: A prospective 6-month pilot study. BMC Public Health 2011;11:786 [http://dx.doi.org/10.1186/1471-2458-11-786] (Clinical trial; non-US government research support)

42. Caponnetto P, Auditore R, Russo C, et al. Impact of an electronic cigarette on smoking reduction and cessation in schizophrenic smokers: A prospective 12-month pilot study. Int J Environ Res Public Health 2013;10(2):446-461. [http://dx.doi.org/10.3390/ijerph10020446]

43. Bahl V, Lin S, Xu N, et al. Comparison of electronic cigarette refill fluid cytotoxicity using embryonic and adult models. Reprod Toxicol 2012;34(4):529-537. [http://dx.doi.org/10.1016/j.reprotox.2012.08.001 (NonUS government research support)

44. Vardavas CI, Anagnostopoulos N, Kougias M, et al. Short-term pulmonary effects of using an electronic cigarette: Impact on respiratory flow resistance, impedance, and exhaled nitric oxide. Chest 2012;141(6):1400-1406. [http://dx.doi.org/10.1378/chest.11-2443] (Non-US government research support)

45. Hartmann-Boyce J, Cahill K, Hatsukami D, et al. Nicotine vaccines for smoking cessation. Cochrane Database Syst Rev 2012;8:CD007072. [http://dx.doi.org/10.1002/14651858.CD007072.pub2] (Meta-analysis review)

46. Tahiri M, Mottillo S, Joseph L, et al. Alternative smoking cessation aids: A meta-analysis of randomized controlled trials. Am J Med 2012;125(6):576-584. [http://dx.doi.org/10.1016/j.amjmed.2011.09.028] (Metaanalysis; non-US government research support)

47. Barnes J, Dong CY, McRobbie H, et al. Hypnotherapy for smoking cessation. Cochrane Database Syst Rev 2010(10):CD001008. [http://dx.doi.org/10.1002/14651858.CD001008.pub2] (Meta-analysis review)

48. White AR, Rampes H, Liu JP, et al. Acupuncture and related interventions for smoking cessation. Cochrane Database Syst Rev 2011(1):CD000009. [http://dx.doi.org/10.1002/14651858.CD000009.pub3] (Meta-analysis review)

49. Law M, Tang JL. A $\mathrm{n}$ analysis of the effectiveness of interventions intended to help people stop smoking. Arch Intern Med 1995;155(18):1933-1941. (Non-US government review research support)

50. Ter Riet G, Kleijnen J, Knipschild P. A meta-analysis of studies into the effect of acupuncture on addiction. Br J Gen Pract 1990;40(338):379-382.

51. American College of Obstetricians and Gynecologists. Committee opinion no. 471: Smoking cessation during pregnancy. Obstet Gynecol 2010;116(5):1241-1244. [http://dx.doi.org/10.1097/AOG.0b013e3182004fcd]

52. Salmasi G, Grady R, Jones J, et al. Environmental tobacco smoke exposure and perinatal outcomes: A systematic review and meta-analyses. Acta Obstet Gynecol Scand 2010;89(4):423-441. [http://dx.doi. org/10.3109/00016340903505748] (Meta-analysis; non-US government review research support)

53. England LJ, Kendrick JS, Wilson HG, et al. Effects of smoking reduction during pregnancy on the birth weight of term infants. Am J Epidemiol 2001;154(8):694-701. (Clinical RCT; PHS government research support)
54. Cook DG, Strachan DP. Health effects of passive smoking - 10: Summary of effects of parental smoking on the respiratory health of children and implications for research. Thorax 1999;54(4):357-366. (Review)

55. Everett-Murphy K, Steyn K, Mathews $C$, et al. The effectiveness of adapted, best practice guidelines for smoking cessation counseling with disadvantaged, pregnant smokers attending public sector antenatal clinics in Cape Town, South Africa. Acta Obstet Gynecol Scand 2010;89(4):478-489. [http://dx.doi. org/10.3109/00016341003605701] (Non-US government review research support)

56. Windsor R, Oncken C, Henningfield J, et al. Behavioral and pharmacological treatment methods for pregnant smokers: Issues for clinical practice. J Am Med Womens Assoc 2000;55(5):304-310. (PHS government research support

57. Swamy GK, Roelands JJ, Peterson BL, et al. Predictors of adverse events among pregnant smokers exposed in a nicotine replacement therapy trial. Am J Obstet Gynecol 2009;201(4):354.el-354.e7. [http://dx.doi. org/10.1016/j.ajog.2009.06.006] (RCT; NIH extramural ad non-US government research support)

58. UK NICE. Smoking Cessation Services in Primary Care, Pharmacies, Local Authorities and Workplaces Particularly for Manual Working Groups, Pregnant Women and Hard to Reach Communities. London NICE, 2008. http://www.nice.org.uk/nicemedia/pdf/ph010guidance.pdf (accessed 1 October 2013).

59. Reddy S.P, James S, Sewpaul R, et al. Umthente Uhlaba Usamila - The 2nd South African National Youth Risk Behaviour Survey 2008. Cape Town: South African Medical Research Council, 2010. http://www.mrc. ac.za/healthpromotion/yrbs_2008_final_report.pdf (accessed 1 October 2013).

60. Panday S, Reddy SP, Bergstrom E. A qualitative study on the determinants of smoking behaviou among adolescents in South Africa. Scand J Public Health 2003;31(3):204-210. [http://dx.doi org/10.1080/14034940210164885]

61. Panday S, Reddy P, Ruiters R, et al. Determinants of smoking among adolescents in the Southern CapeKaroo region, South Africa. Health Promot Int 1997;22(3):207-217.

62. Brook JS, Morojele NK, Brook DW, et al. Predictors of cigarette use among South African adolescents. In J Behav Med 2005;12(4):207-217. [http://dx.doi.org/10.1207/s15327558ijbm1204_1] (NIH extramural and PHS government research support)

63. Foulds J. Smoking Cessation in Young People Should we do more to help young smokers to quit? London: NICE, 2000. http://www.nice.org.uk/nicemedia/documents/smokingcessation_youngpeople.pdf (accessed 1 October 2013).

64. Farkas AJ, Distefan JM, Choi WS, et al. Does parental smoking cessation discourage adolescent smoking? Prev Med 1999;28(3):213-218. [http://dx.doi.org/10.1006/pmed.1998.0451] (PHS government research support)

65. Bates MN, Khalakdina A, Pai M, et al. Risk of tuberculosis from exposure to tobacco smoke: A systematic review and meta-analysis. Arch Intern Med 2007;167(4):335-342.

66. Slama K, Chiang CY, Enarson DA, et al. Tobacco and tuberculosis: A qualitative systematic review and meta-analysis. Int J Tuberc Lung Dis 2007;11(10):1049-1061.

67. Lin HH, Ezzati M, Murray M. Tobacco smoke, indoor air pollution and tuberculosis: A systematic review and meta-analysis. PLoS Med 2007;4(1):e20. [http://dx.doi.org/10.1371/journal.pmed.0040020]

68. Brunet L, Pai M, Davids V, et al. High prevalence of smoking among patients with suspected tuberculosis in South Africa. Eur Respir J 2010;38(1):139-146. [http://dx.doi.org/10.1183/09031936.00137710]

69. Sereno AB, Soares EC, Lapa ESJR, et al. Feasibility study of a smoking cessation intervention in Directly Observed Therapy Short-Course tuberculosis treatment clinics in Rio de Janeiro, Brazil. Rev Panam Salud Publica 2012;32(6):451-456. (Non-US government research support)

70. Awaisu A, Nik Mohamed MH, Mohamad Noordin N, et al. The SCIDOTS Project: Evidence of benefits of an integrated tobacco cessation intervention in tuberculosis care on treatment outcomes. Subst Abuse Treat Prev Policy 2011;6:26. [http://dx,doi.org/10.1186/1747-597X-6-26 (Multi-centre, controlled clinical trial; non-US government research support)

7. van Zyl-Smit RN, Dheda K. Partners in crime: The deadly synergy of tuberculosis and tobacco smoke? Mycobacterial Diseases 2012;2:2. [http://dx.doi.org/10.4172/2161-1068.1000e111]

72. Lifson AR, Lando HA. Smoking and HIV: Prevalence, health risks, and cessation strategies. Curr HIV/AIDS Rep 2012;9(3):223-230. [http://dx.doi.org/10.1007/s11904-012-0121-0] (Review)

73. Ferketich AK, Diaz P, Browning KK, et al. Safety of varenicline among smokers enrolled in the lung HIV study. Nicotine Tob Res 2013;15(1):247-254. [http://dx.doi.org/10.1093/ntr/nts121]

74. Rahmanian S, Wewers ME, Koletar S, et al. Cigarette smoking in the HIV-infected population. Proc Am Thorac Soc 2011;8(3):313-319. [http://dx.doi.org/10.1513/pats.201009-058WR] (NIH extramural and nonUS government research support)

75. Zevin S, Benowitz NL. Drug interactions with tobacco smoking. An update. Clin Pharmacokine 1999;36(6):425-438. (PHS government review research support)

76. Kalow W, Tang BK. Caffeine as a metabolic probe: Exploration of the enzyme-inducing effect of cigarette smoking. Clin Pharmacol Ther 1991;49(1):44-48. (PHS government and non-US government research support)

77. van der Meer RM, Willemsen MC, Smit F, et al. Smoking cessation interventions for smokers with current or past depression. Cochrane Database Syst Rev 2013;8:CD006102. [http://dx.doi. with current or past depression. Coch2]
org/10.1002/14651858.CD006102.pub2]

78. Ziedonis D, Hitsman B, Beckham JC, et al. Tobacco use and cessation in psychiatric disorders National Institute of Mental Health report. Nicotine Tob Res 2008;10(12):1691-1715. [http://dx.doi org/10.1080/14622200802443569] (NIH extramural and non-US government research support)

79. Moylan S, Gustavson K, Karevold E, et al. The impact of smoking in adolescence on early adult anxiety symptoms and the relationship between infant vulnerability factors for anxiety and early adult anxiety symptoms: The TOPP Study. PLoS One 2013;8(5):e63252. [http://dx.doi.org/10.1371/journal pone.0063252] (Non-US government research support)

80. Rigotti NA, Clair C, Munafo MR, et al. Interventions for smoking cessation in hospitalised patients. Cochrane Database Syst Rev 2012;5:CD001837. [http://dx.doi.org/10.1002/14651858.CD001837.pub3] (Meta-analysis; NIH extramural and non-US government review research support)

81. Sorensen LT, Karlsmark T, Gottrup F. Abstinence from smoking reduces incisional woun infection: A randomized controlled trial. Ann Surg 2003;238(1):1-5. [http://dx.doi.org/10.1097/01. SLA.0000074980.39700.31] (Comparative, clinical RCT; non-US government research support)

82. Moller AM, Villebro N, Pedersen T, et al. Effect of preoperative smoking intervention on postoperative complications: A randomised clinical trial. Lancet 2002;359(9301):114-117. [http://dx.doi.org/10.1016/ S0140-6736(02)07369-5] (Multi-centre, clinical RCT; non-US government research support)

83. Buist AS, Sexton GJ, Nagy IM, et al. The effect of smoking cessation and modification on lung function. Am Rev Respir Dis 1976;114(1):115-122. (PHS government research support)
Restist

84. Beckers S, Camu F. The anesthetic risk of tobacco smoking. Acta Anaesthesiol Belg 1991;42(1):45-56. (Review)

85. Heatherton TF, Kozlowski LT, Frecker RC, et al. The Fagerström test for Nicotine Dependence: A revision of the Fagerström Tolerance Questionnaire. Br J Addict 1991;86(9):1119-1127.

86. Fagerström K, Russ C, Yu CR, et al. The Fagerström Test for Nicotine Dependence as a predicto of smoking abstinence: A pooled analysis of varenicline clinical trial data. Nicotine Tob Res 2012;14(12):1467-1473. [http://dx.doi.org/10.1093/ntr/nts018] (Clinical phase II RCT; non-US government research support) 